Article

\title{
Predicting Shifts in the Suitable Climatic Distribution of Walnut (Juglans regia L.) in China: Maximum Entropy Model Paves the Way to Forest Management
}

\author{
Xiang $X u^{\circledR}$, Huayong Zhang $*^{\mathbb{D}}$, Junjie Yue, Ting Xie, Yao Xu and Yonglan Tian \\ Research Center for Engineering Ecology and Nonlinear Science, North China Electric Power University, \\ Beijing 102206, China; xuxiang229@163.com (X.X.); yuejj2312@163.com (J.Y.); tingxie1995@163.com (T.X.); \\ xy1737_cool@126.com (Y.X.); woaimokegege@126.com (Y.T.) \\ * Correspondence: rceens@ncepu.edu.cn; Tel.: +86-010-6177-3936
}

Received: 15 November 2017; Accepted: 26 February 2018; Published: 28 February 2018

\begin{abstract}
Cultivation of woody oil plants in environmentally suitable habitats is a successful ecological solution for oil development and forest management. In this study, we predicted the influences of future climate change on the potentially suitable climatic distribution of an important woody oil plant species (walnut; Juglans regia L.) in China based on given climate change scenarios and the maximum entropy (MaxEnt) model. The MaxEnt model showed that the minimum temperature of the coldest month and annual precipitation were the most important determinant variables limiting the geographical distribution of J. regia. We have found that the current suitable environmental habitat of J. regia is mainly distributed in central and southwestern China. Results of the MaxEnt model showed that global warming in the coming half-century may lead to an increase in the area size of environmentally suitable habitats for J. regia in China, indicating more lands available for artificial cultivation and oil production. However, those suitable habitat gains may be practically inaccessible due to over-harvest and urban development, and effective management strategies are urgently needed to establish those forests. This research will provide theoretical suggestions for the protection, cultivation management, and sustainable utilization of J. regia resources to face the challenge of global climate change.
\end{abstract}

Keywords: species distribution; MaxEnt model; Juglans regia; climate change; suitable habitat

\section{Introduction}

Global climate change is occurring at an unprecedented rate. Average temperatures have increased by $0.85^{\circ} \mathrm{C}$ in the last century and are predicted to continue to increase by a minimum of $0.3-1.7^{\circ} \mathrm{C}$ to a maximum of $2.6-4.8^{\circ} \mathrm{C}$ by 2100 [1]. Climate has significantly affected the growth and reproduction of plants and has therefore become a dominating variable determining the geographical distribution of plant species [2-4]. Due to the threat of global warming, the lack of rational utilization, and the lack of effective protection on wild plant resources, some important economic plant species have sharply contracted their geographical distribution, or even gone extinct [5]. Artificial cultivation is one of the most effective tools to conserve and restore those economically important plants in order to face the challenge of global climate change [6]. Meanwhile, artificial cultivation will also meet the market demand for those plant resources [7]. However, successful artificial cultivation of high-quality plants depends on both good germplasm resources and suitable environmental conditions [8,9]. Accordingly, identifying the suitable environmental habitats for the target plant species as affected by global climate change has great economic and ecological value.

Species distribution models (SDMs) are powerful tools to assess the current and future potential geographical distributions of target species, relying on the statistical correlation between species 
existence and corresponding environmental variables [10-13]. Among SDMs, the maximum entropy (MaxEnt) model is the most popular one to simulate species distribution based on species presence-only records, which are usually readily available from digital specimen museums and published literature [14-16]. The MaxEnt model has been widely used to evaluate the relationship between species distribution and determinant variables and to predict the response of species geographical distribution to global climate change [17-20]. Many studies have found that the MaxEnt model typically outperforms other methods in terms of high predictive accuracy and high tolerance to extremely small sample size [21-23].

Commonly known as the walnut, Juglans regia $\mathrm{L}$. is a deciduous tree species belonging to the genus Juglans and family Juglandaceae, and is ranked first among the four nut types in the world [24]. It is widely disseminated in Asia, North and South America, Europe, South Africa, Australia, and New Zealand [25]. J. Regia originated in China and has a long history of cultivation [26]. Moreover, China is the largest consumer of vegetable oil in the world, with an annual consumption of 30 million tons [27]. However, nearly seventy percent of the vegetable oil consumption in China depends on imports [27]. Accordingly, J. Regia has gained attention as an important local woody oil plant species in China, which can be used as the raw material to develop the local woody oil industry [28]. Therefore, it is necessary and important to predict how global climate change will impact the potentially suitable climatic distribution of $J$. regia in China.

Here, we predicted the current and future suitable climatic distributions of J. regia given global climate change using the MaxEnt model. We aimed to (i) explore the relative importance of environmental variables on the geographical range of J. regia; (ii) evaluate the ecological niches and environmental tolerance of J. regia; (iii) delineate the environmentally suitable habitat maps for J. regia; (iv) indicate the habitat change of J. regia responding to global climate change; and (v) ultimately provide the theoretical basis for protective strategy formulation and cultivation management of this woody oil plant species.

\section{Materials and Methods}

\subsection{Species Occurrence Records}

We collected the specimen records of J. regia from the Chinese Virtual Herbarium (CVH) [29] and the Global Biodiversity Information Facility (GBIF) [30]. Cultivated records were identified based on the specimen label and then removed to avoid anthropogenic disturbance. To match the spatial resolution of environmental variables $(\sim 1 \times 1 \mathrm{~km}$, detailed below), we performed spatial filtering of presence points on a $1 \mathrm{~km}^{2}$ grid. Finally, we obtained 543 occurrence points of $J$. regia in China at a spatial resolution of $1 \mathrm{~km}$ (Figure 1; Appendix A).

\subsection{Environmental Variables}

We selected 33 environmental variables-16 bioclimatic, 3 topographical, and 14 soil variables-to model the potentially suitable environmental distribution of J. regia (Table 1). Bioclimatic variables were downloaded from the global database WorldClim (http:/ /www.worldclim.org/) at a spatial resolution of 30 arcseconds (ca. $1 \times 1 \mathrm{~km}$ ) [31]. Raster layers in WorldClim were obtained by spatial interpolation on monthly values of temperature and precipitation ranging over the time period from 1950 to 2000 from numerous weather stations around the world [31]. WorldClim provided 19 bioclimatic variables, but only 16 variables were used in this study because 3 variables-isothermality (Bio3), precipitation of the driest month (Bio14), precipitation seasonality (Bio15)—are clearly biased when projected to past and future scenarios, and thus must be excluded [32,33]. We also extracted the elevation variable from WorldClim and calculated a topographical variable (i.e., aspect) based on elevation in ArcGIS 10.3 (ESRI, Redlands, CA, USA). Then, the elevation variable was projected in a meter coordinate system and another topographical variable (i.e., slope) was calculated based on elevation in ArcGIS 10.3. Soil variables were obtained from the Harmonized World Soil Database (HWSD) (http:/ / www. 
iiasa.ac.at/web/home/research/researchPrograms/water/HWSD.html), which contains raster data layers on key soil properties at the spatial resolution of 30 arcseconds [34].

Table 1. Environmental variables used in this study and their percentage contribution.

\begin{tabular}{|c|c|c|c|c|}
\hline Category & Variable & Description & Unit & Contribution $(\%)$ \\
\hline \multirow{16}{*}{ Climate } & Bio1 & Annual Mean Temperature & ${ }^{\circ} \mathrm{C}$ & \\
\hline & Bio2 & $\begin{array}{l}\text { Mean Diurnal Range (Mean of monthly } \\
\text { (max temp - min temp)) }\end{array}$ & ${ }^{\circ} \mathrm{C}$ & \\
\hline & Bio4 & $\begin{array}{l}\text { Temperature Seasonality (standard } \\
\text { deviation } \times 100 \text { ) }\end{array}$ & ${ }^{\circ} \mathrm{C}$ & \\
\hline & Bio5 & Max Temperature of Warmest Month & ${ }^{\circ} \mathrm{C}$ & 2.0 \\
\hline & Bio6 & Min Temperature of Coldest Month & ${ }^{\circ} \mathrm{C}$ & 63.9 \\
\hline & Bio7 & Temperature Annual Range (Bio5 - Bio6) & ${ }^{\circ} \mathrm{C}$ & 7.1 \\
\hline & $\operatorname{Bio} 8$ & Mean Temperature of Wettest Quarter & ${ }^{\circ} \mathrm{C}$ & \\
\hline & Bio9 & Mean Temperature of Driest Quarter & ${ }^{\circ} \mathrm{C}$ & \\
\hline & Bio10 & Mean Temperature of Warmest Quarter & ${ }^{\circ} \mathrm{C}$ & \\
\hline & Bio11 & Mean Temperature of Coldest Quarter & ${ }^{\circ} \mathrm{C}$ & \\
\hline & Bio12 & Annual Precipitation & $\mathrm{mm}$ & 12.6 \\
\hline & Bio13 & Precipitation of Wettest Month & $\mathrm{mm}$ & \\
\hline & Bio16 & Precipitation of Wettest Quarter & $\mathrm{mm}$ & \\
\hline & Bio17 & Precipitation of Driest Quarter & $\mathrm{mm}$ & \\
\hline & Bio18 & Precipitation of Warmest Quarter & $\mathrm{mm}$ & \\
\hline & Bio19 & Precipitation of Coldest Quarter & $\mathrm{mm}$ & \\
\hline \multirow{3}{*}{ Topography } & Elevation & & $\mathrm{m}$ & 5.1 \\
\hline & Slope & & $\circ$ & 2.8 \\
\hline & Aspect & & $\mathrm{rad}$ & 0.8 \\
\hline \multirow{14}{*}{ Soil } & t_bulk_den & Topsoil Bulk Density & $\mathrm{kg} / \mathrm{dm}^{3}$ & 0.9 \\
\hline & s_bulk_den & Subsoil Bulk Density & $\mathrm{kg} / \mathrm{dm}^{3}$ & 0.5 \\
\hline & t_clay & Topsoil Clay Fraction & $\%$ & 1.7 \\
\hline & s_clay & Subsoil Clay Fraction & $\%$ & \\
\hline & $\mathrm{t}$ _gravel & Topsoil Gravel Content & $\%$ & 0.3 \\
\hline & s_gravel & Subsoil Gravel Content & $\%$ & 0.0 \\
\hline & t_ph_h20 & Topsoil pH $\left(\mathrm{H}_{2} \mathrm{O}\right)$ & $-\log \left(\mathrm{H}^{+}\right)$ & 0.3 \\
\hline & s_ph_h20 & Subsoil $\mathrm{pH}\left(\mathrm{H}_{2} \mathrm{O}\right)$ & $-\log \left(\mathrm{H}^{+}\right)$ & \\
\hline & t_esp & $\begin{array}{l}\text { Topsoil Sodicity (ESP, exchangeable } \\
\text { sodium percentage) }\end{array}$ & $\%$ & 0.4 \\
\hline & s_esp & $\begin{array}{l}\text { Subsoil Sodicity (ESP, exchangeable } \\
\text { sodium percentage) }\end{array}$ & $\%$ & 0.2 \\
\hline & t_sand & Topsoil Sand Fraction & $\%$ & 0.2 \\
\hline & s_sand & Subsoil Sand Fraction & $\%$ & 0.1 \\
\hline & t_silt & Topsoil Silt Fraction & $\%$ & 0.5 \\
\hline & s_silt & Subsoil Silt Fraction & $\%$ & 0.6 \\
\hline
\end{tabular}

The 19 variables selected through the multicollinearity test were used in MaxEnt modeling.

To predict the potentially suitable environmental distribution and suitable habitat change under future climate change, we collected projected bioclimatic variables from low to high representative concentration pathways (RCP 2.6, RCP 4.5, RCP 6.0, and RCP 8.5) for 2041-2060 and 2061-2080. We chose the BCC-CSM1.1 (Beijing Climate Centre-Climate System Modelling 1.1; available from www.worldclim.com) as it is one of the most widely used general circulation models (GCMs) in the Asia region $[35,36]$. We assumed that the 3 topographical and 14 soil variables remain unchanged in the coming 70 years. 


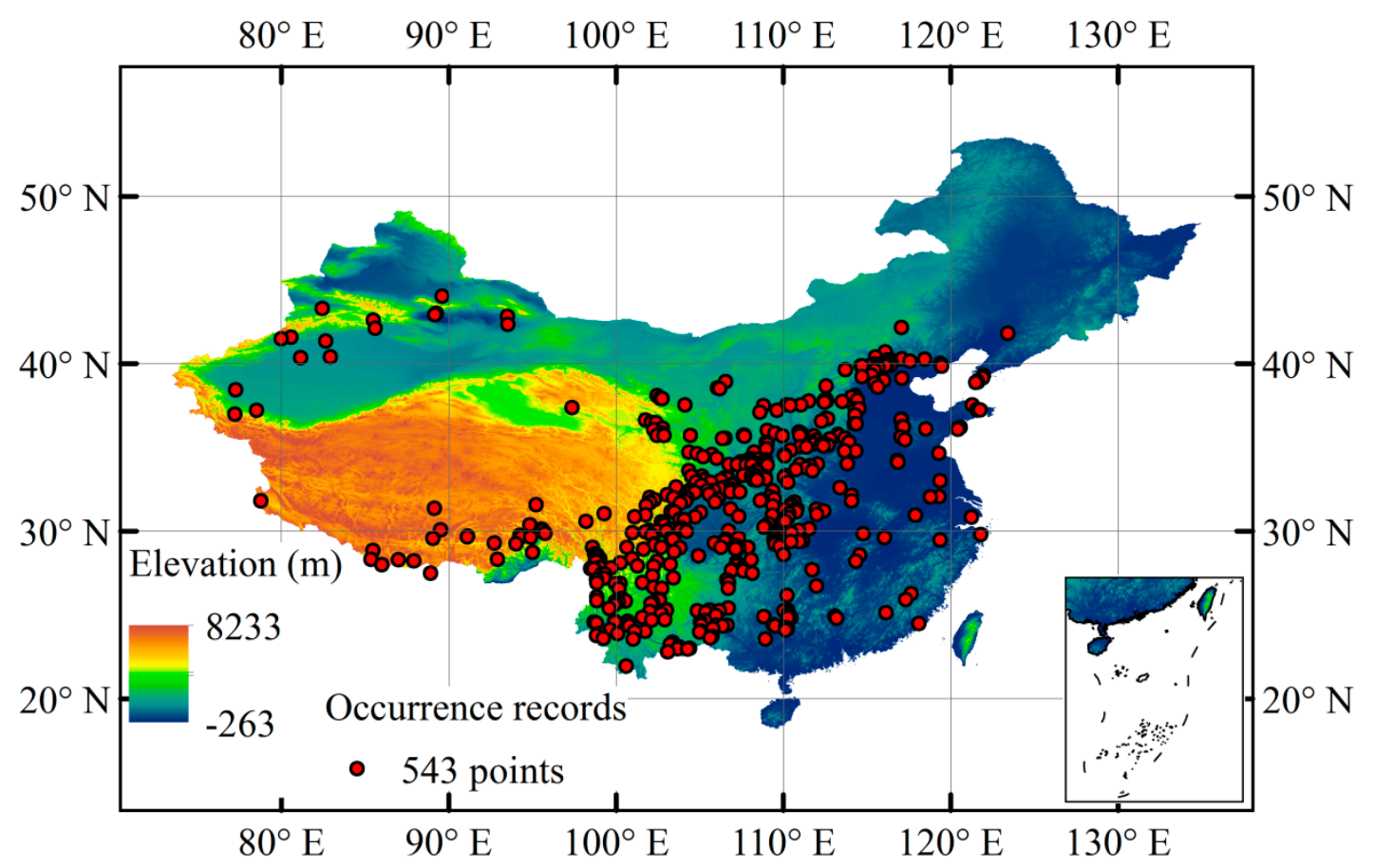

Figure 1. Spatial distribution of occurrence records of Juglans regia and elevation in China.

\subsection{Correlation Analysis and Principal Component Analysis}

The Pearson correlation coefficients $(r)$ among the 16 bioclimatic variables, 3 topographical variables, and 14 soil variables were calculated in ArcGIS 10.3 (band collection statistics tool). If a pair of variables were strongly correlated $(|r| \geq 0.8)$, one of the variables was removed to avoid the violation of statistical assumptions and avoid model predictions induced by multicollinearity among environmental variables $[37,38]$. To select the remaining variables, we conducted principal component analysis (PCA) to reveal the relative importance of each variable for the potentially suitable environmental distribution of J. regia based on its 543 occurrence points. The variables showing the higher ecological importance for J. regia were retained in the following analysis.

\subsection{MaxEnt Models}

MaxEnt 3.3.3. was used to project the potentially suitable environmental distribution of J. regia [39]. In MaxEnt 3.3.3k, we set the number of random background points as 10,000. We randomly selected $80 \%$ of J. regia occurrence points to train the MaxEnt model and the remaining points to validate the model. Five replicates were run to carry out the MaxEnt model. We used Jackknife to evaluate the relative importance of each environmental variable. The area under the receiver operating characteristic curve (AUC) was used to estimate the accuracy of the model predictions [40,41].

The MaxEnt model generated continuous probability values for the presence of $J$. regia, ranging from 0 to 1 . To delineate the presence/absence map of $J$. regia, those continuous probability values were converted to the binary prediction (i.e., a pixel is considered as either suitable or not for the presence of J. regia) based on a threshold probability value. This threshold probability was determined according to the 'maximum training sensitivity plus specificity' criterion. This criterion optimizes the trade-off between sensitivity and specificity using the training data and, therefore, has been recognized as one of the best threshold selection methods [42-44]. This presence/absence map was then used to analyze the spatial range changes of J. regia.

To delineate the pattern of predicted habitat change, we defined 'habitat gain' where a habitat is not suitable for J. regia under the current climate conditions, but becomes suitable under the future climate. If some habitat is suitable for J. regia under the current climate, but no longer suitable under 
the future climate, we called it 'habitat loss'. If a suitable habitat under the current climate is still suitable for J. regia under the future climate, we defined it as 'unchanged'. The centroids of suitable habitats were also calculated under current and future conditions, and were helpful as they clearly show the shift of the suitable habitat responding to global climate change.

\section{Results}

\subsection{Model Evaluation and Variables' Contribution}

We found weak correlations among topographical variables. Therefore, three topographical variables were retained in the MaxEnt model. The bioclimatic and soil variables showing the higher ecological importance for J. regia are shown in Tables A1 and A2. Finally, we obtained 19 variables to be incorporated in the MaxEnt software: maximum temperature of the warmest month (MTWM), minimum temperature of the coldest month (MTCM), temperature annual range (TAR), annual precipitation (AP), elevation, slope, aspect, topsoil bulk density (t_bulk_den), subsoil bulk density (s_bulk_den), topsoil clay fraction (t_clay), topsoil gravel content (t_gravel), subsoil gravel content (s_gravel), topsoil $\mathrm{pH}\left(\mathrm{H}_{2} \mathrm{O}\right)$ (t_ph_h20), topsoil sodicity (ESP, exchangeable sodium percentage) (t_esp), subsoil sodicity (ESP, exchangeable sodium percentage) (s_esp), topsoil sand fraction (t_sand), subsoil sand fraction (s_sand), topsoil silt fraction (t_silt), and subsoil silt fraction (s_silt).

The MaxEnt model for J. regia showed a reliable prediction with an AUC of $0.843( \pm 0.008)$, greater than the 0.5 of a random model. MTCM contributed most to the model, followed by AP and TAR (Table 1). Those three variables cumulatively contributed $83.6 \%$ to the geographical distribution of J. regia in China. In particular, the cumulative contributions of bioclimatic, topographical, and soil variables were $85.6 \%, 8.7 \%$, and $5.7 \%$, respectively.

\subsection{Response of Variables to Suitability}

Response curves illustrate how the probability of J. regia presence changes as each environmental variable changes (Figure 2). The habitat suitability of J. regia is hump-shaped with increasing MTCM, $\mathrm{AP}$, and TAR. We obtained the threshold probability (i.e., 0.31) indicative of J. regia presence based on the rule of maximum training sensitivity plus specificity. MTCM ranging from $-14.8^{\circ} \mathrm{C}$ to $7.7^{\circ} \mathrm{C}$, AP ranging from $480 \mathrm{~mm}$ to $1804 \mathrm{~mm}$, and TAR ranging from $17.7^{\circ} \mathrm{C}$ to $44.1^{\circ} \mathrm{C}$ are suitable for the distribution of J. regia.
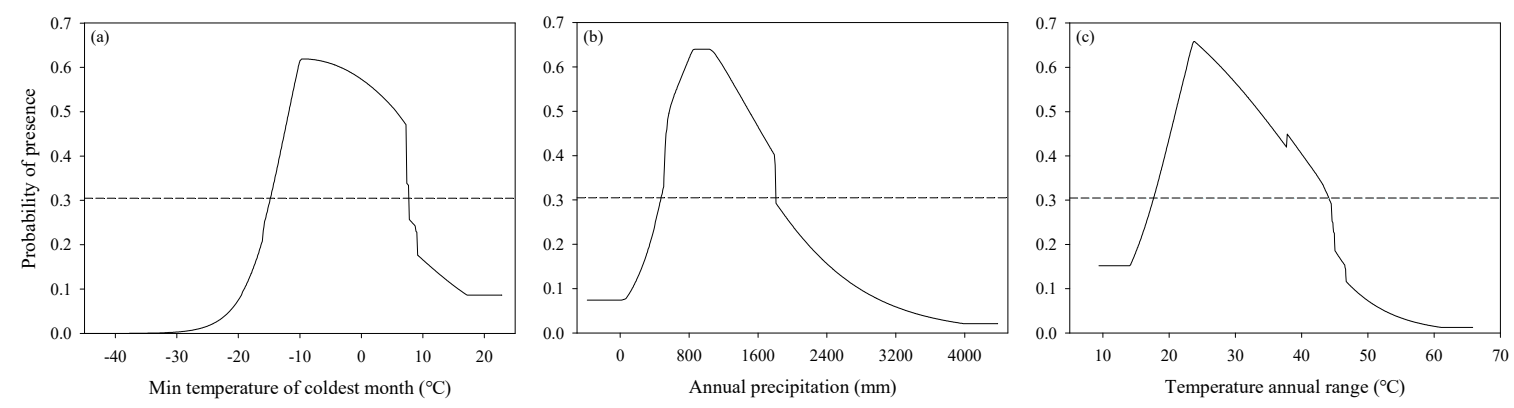

Figure 2. The response curves of three main variables contributing to the habitat suitability of Juglans regia. (a) Min temperature of the coldest month $\left({ }^{\circ} \mathrm{C}\right)$; (b) annual precipitation (mm); (c) temperature annual range $\left({ }^{\circ} \mathrm{C}\right)$. Dashed lines represent the threshold probability $(0.31)$ indicative of species presence.

\subsection{Current Potentially Suitable Climatic Distribution}

The predicted potentially suitable climatic distribution of J. regia based on observed occurrences and current environmental conditions projected by the MaxEnt model is shown in Figure 3. The results show that the suitable habitats are primarily located in central and southwestern China, mainly 
including Beijing, Hebei, Ningxia, Shaanxi, Shanxi, Shandong, Henan, Chongqing, Hubei, Yunnan, Guizhou, southern Liaoning, southern Gansu, and eastern Sichuan.

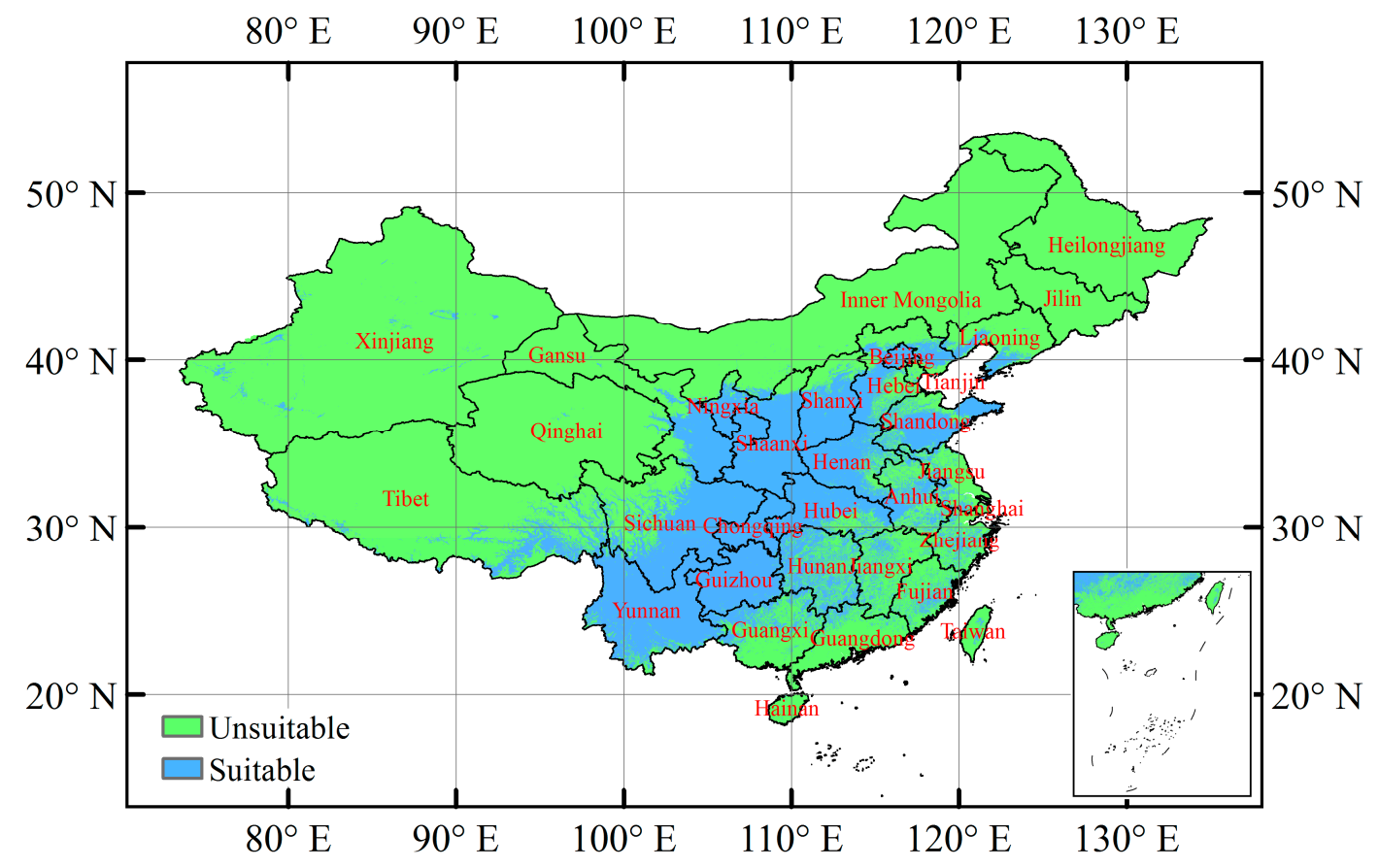

Figure 3. Current suitable climatic distribution of Juglans regia in China.

\subsection{Future Potentially Suitable Climatic Distribution}

The predicted future potentially suitable climatic distributions of $J$. regia under RCP 2.6, RCP 4.5, RCP 6.0, and RCP 8.5 climate change scenarios for 2041-2060 and 2061-2080 are shown in Figure 4. The results show that the suitable habitats under future climate change scenarios are mainly distributed in central, southwestern, and northwestern China. For the period of 2041-2060, the suitable habitats are mainly located in Beijing, Hebei, Ningxia, Shaanxi, Shanxi, Shandong, Henan, Sichuan, Chongqing, Hubei, Anhui, Yunnan, Guizhou, Hunan, southwestern Liaoning, southern Gansu, and southeastern Tibet under RCP 2.6, RCP 4.5, and RCP 6.0 (Figure 4a,c,e), and increase considerably in northwestern and southeastern China (mainly including Xinjiang, Zhejiang, and Jiangxi) under RCP 8.5 (Figure 4g). For the period of 2061-2080, the area size of suitable habitats for J. Regia continues to significantly increase in northwestern China (mainly including Xinjiang and the west of Inner Mongolia) under RCP 2.6, RCP 4.5, RCP 6.0, and RCP 8.5 (Figure 4b,d,f,h). Overall, the area size of suitable habitats for J. regia gradually increases along the climate scenario gradient (from RCP 2.6 to RCP 8.5 ) in the period of 2061-2080 (Table 2).

\subsection{Future Changes in the Climatically Suitable Habitat Area}

Most (90.6-96.7\%) of the suitable habitat area for J. regia under different future climate scenarios remains unchanged (Figure 5, Table 2). The results show that the suitable habitat area increases in central and western China (mainly including Xinjiang, southern Inner Mongolia, central Gansu, northern Shaanxi, northern Shanxi, northern Hebei, southwestern Liaoning, and northwestern Sichuan), while decreasing a little in southeastern China (mainly including Zhejiang, Fujian, Hunan, northern Guangxi, and southern Yunnan) (Figure 5). Under RCP 2.6, RCP 6.0, and RCP 8.5, the gain in suitable habitat area increases from the period of 2041-2060 to the period of 2061-2080 (RCP 2.6: from $16.8 \%$ to $19.8 \%$; RCP 6.0 : from $20.5 \%$ to $43.7 \%$; RCP 8.5 : from $40.6 \%$ to $82.5 \%$ ). Under all future climate scenarios, the loss of suitable habitat area increases from the period of 2041-2060 to the period of 2061-2080 (RCP 2.6: from 3.3\% to 9.4\%; RCP 4.5: from 7.7\% to $8.4 \%$; RCP 6.0: from $6.7 \%$ to $7.5 \%$; RCP 
8.5: from $4.7 \%$ to $8.9 \%$ ). Thus, the suitable habitat area of $J$. regia expands along the temporal gradient (from the period of 2041-2060 to 2061-2080) under both RCP 6.0 and RCP 8.5, while contracting under both RCP 2.6 and RCP 4.5 .

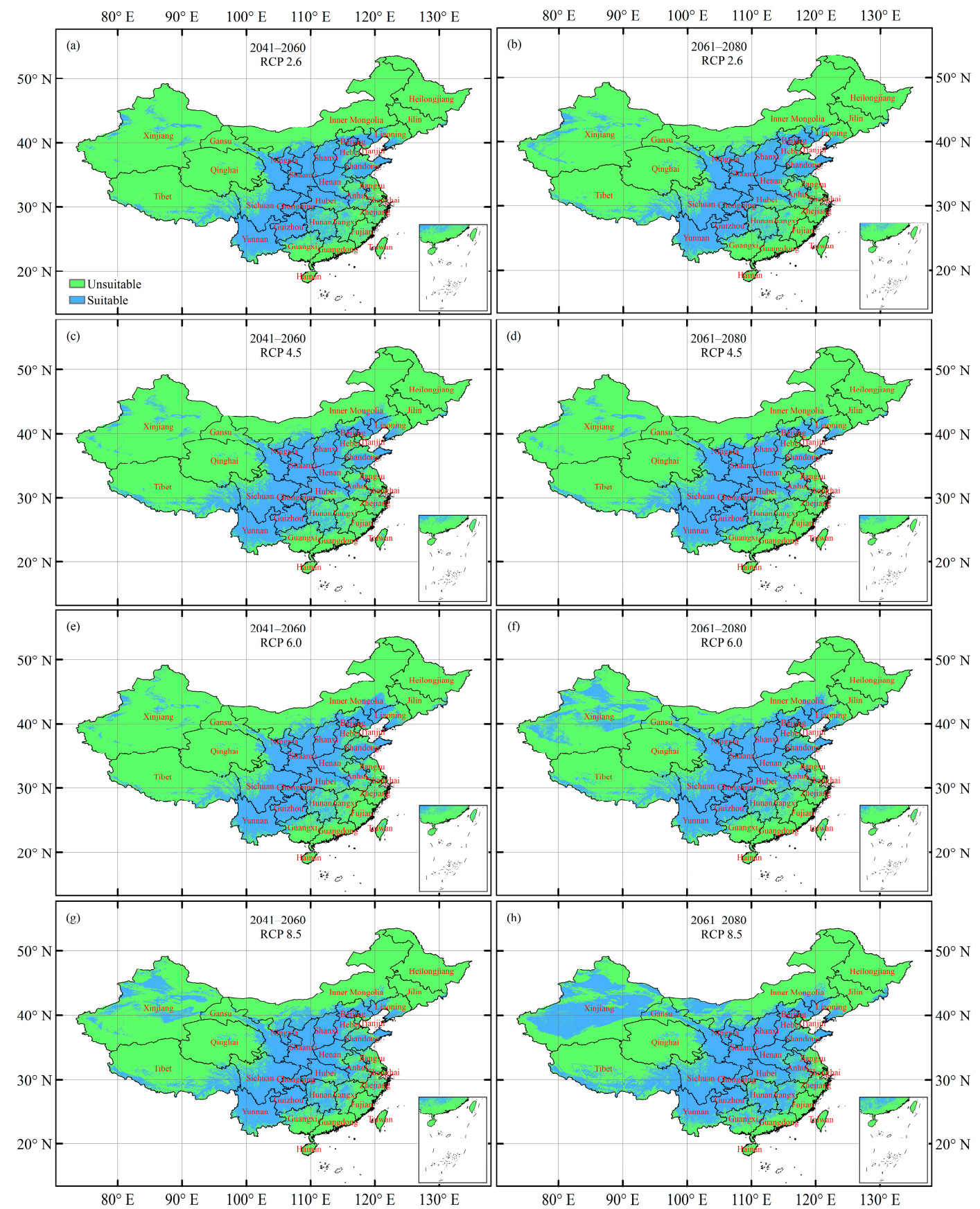

Figure 4. Potentially suitable climatic distribution of Juglans regia under different climate change scenarios in China. (a) Period of 2041-2060 in the representative concentration pathway (RCP) 2.6 climate scenario; (b) period of 2061-2080 in the RCP 2.6 climate scenario; (c) period of 2041-2060 in the RCP 4.5 climate scenario; (d) period of 2061-2080 in the RCP 4.5 climate scenario; (e) period of 2041-2060 in the RCP 6.0 climate scenario; (f) period of 2061-2080 in the RCP 6.0 climate scenario; (g) period of 2041-2060 in the RCP 8.5 climate scenario; (h) period of 2061-2080 in the RCP 8.5 climate scenario. 

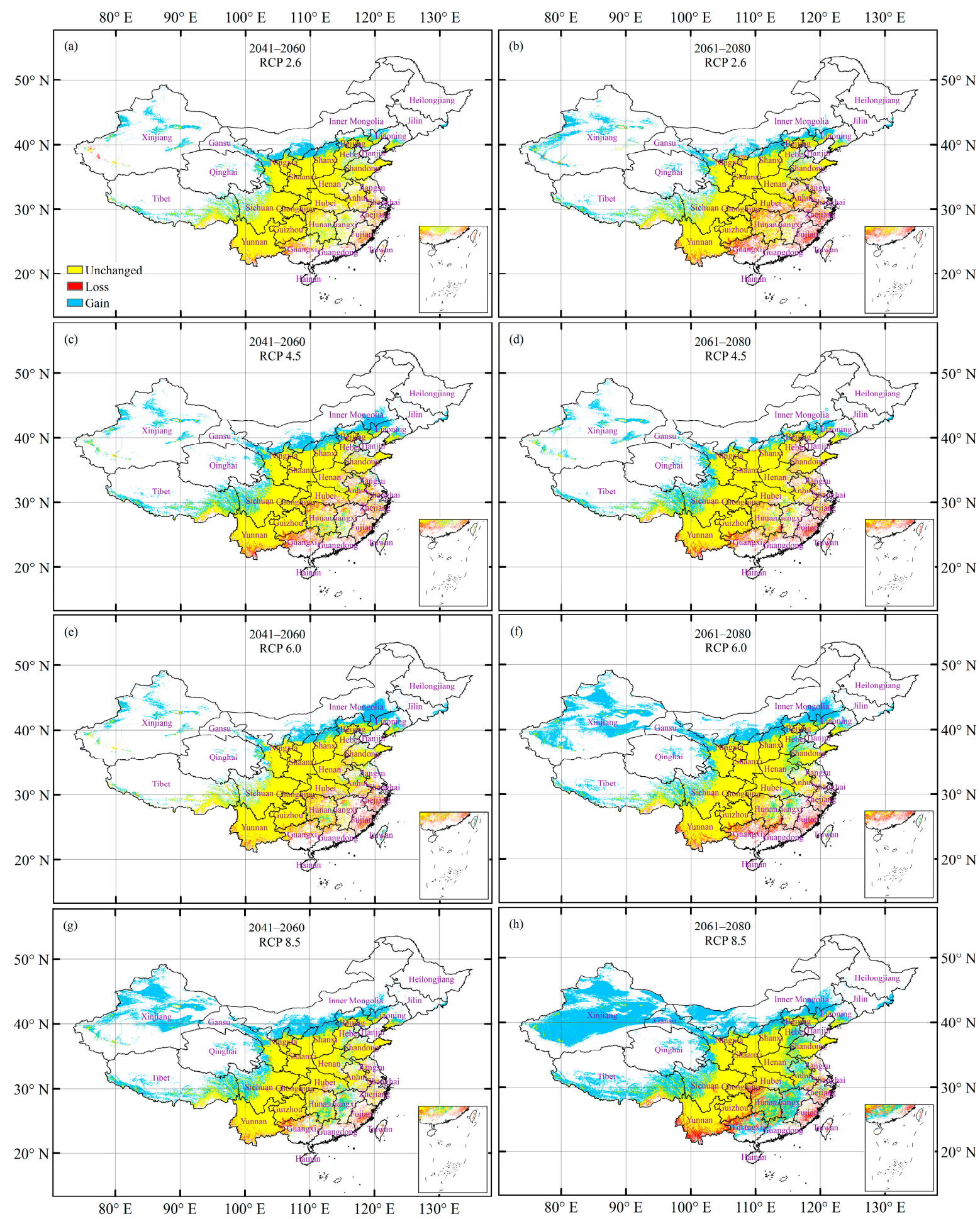

Figure 5. Changes in the climatically suitable habitat of Juglans regia under different climate change scenarios around the world. (a) Period of 2041-2060 in the RCP 2.6 climate scenario; (b) period of 2061-2080 in the RCP 2.6 climate scenario; (c) period of 2041-2060 in the RCP 4.5 climate scenario; (d) period of 2061-2080 in the RCP 4.5 climate scenario; (e) period of 2041-2060 in the RCP 6.0 climate scenario; (f) period of 2061-2080 in the RCP 6.0 climate scenario; (g) period of 2041-2060 in the RCP 8.5 climate scenario; (h) period of 2061-2080 in the RCP 8.5 climate scenario. 
Table 2. Predicted changes in the climatically suitable habitat area (\%) of Juglans regia under different climate change scenarios around the world.

\begin{tabular}{cccccc}
\hline Future Climate Change Scenario & Unchanged & Loss & Gain & Total change (= Gain - Loss) ${ }^{\mathbf{1}}$ \\
\hline \multirow{3}{*}{ Period of } & RCP 2.6 & 96.7 & 3.3 & 16.8 & 13.4 \\
2041-2060 & RCP 4.5 & 92.3 & 7.7 & 25.7 & 18.0 \\
& RCP 6.0 & 93.3 & 6.7 & 20.5 & 13.7 \\
& RCP 8.5 & 95.3 & 4.7 & 40.6 & 35.8 \\
Period of & RCP 2.6 & 90.6 & 9.4 & 19.8 & 10.4 \\
2061-2080 & RCP 4.5 & 91.6 & 8.4 & 19.2 & 10.7 \\
& RCP 6.0 & 92.5 & 7.5 & 43.7 & 73.2 \\
\hline
\end{tabular}

${ }^{1}$ Positive values indicate suitable habitat area expansion.

\subsection{Suitable Climatic Habitat Shift}

The centroid of the current suitable habitat for J. regia is located in eastern Sichuan (Figure 6). Under RCP 2.6, the centroid shifts to a northwestern position by the period of 2041-2060, and then to a further northwest position by the period of 2061-2080. Under both RCP 6.0 and RCP 8.5, the shift of the centroid retained this northwest tendency. Overall, the distributional shift of climatically suitable habitats expressed a northwest tendency along the temporal gradient (from current to the period of 2041-2060 and then to 2061-2080) (Figure 6).

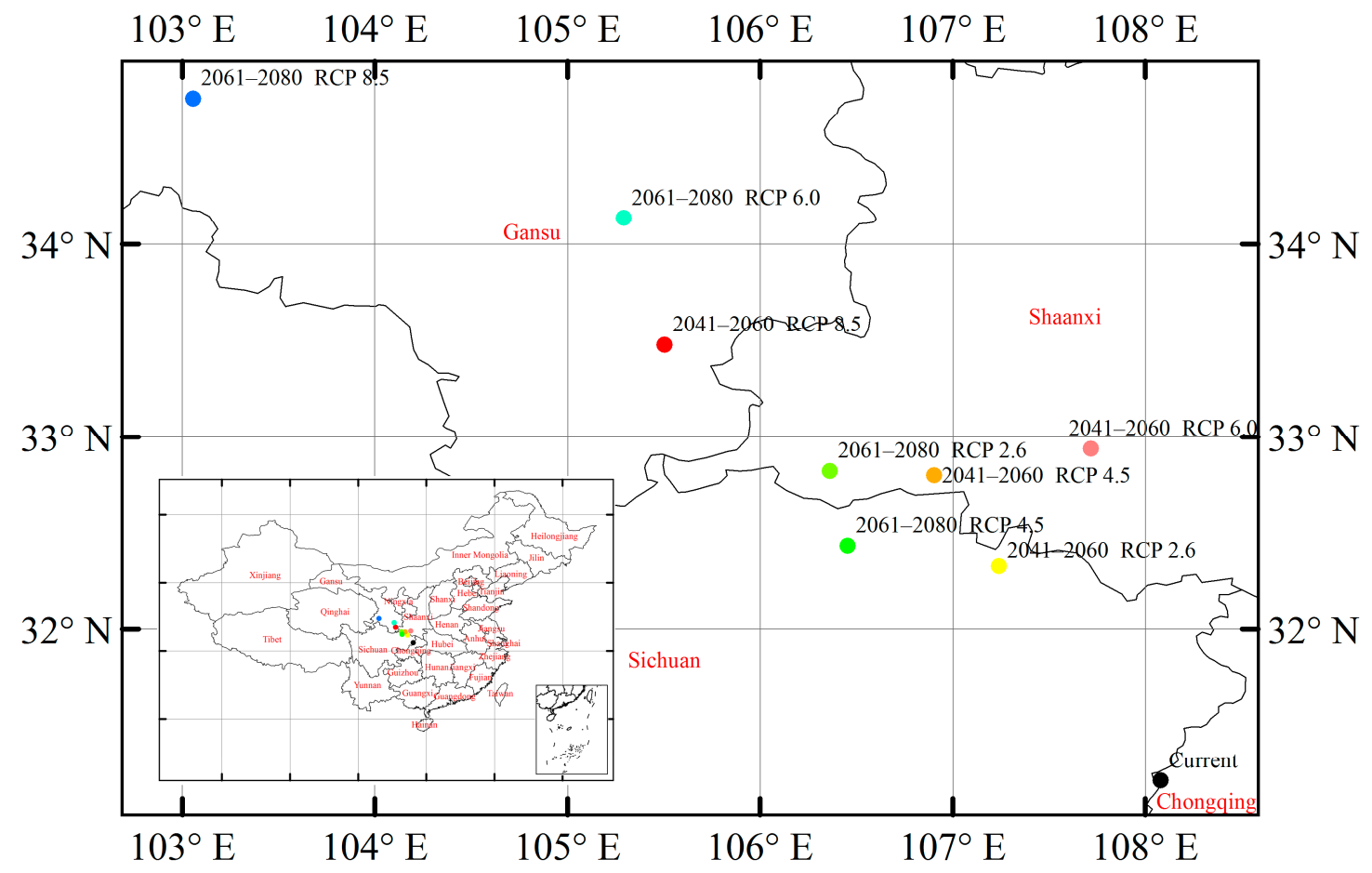

Figure 6. Shifts in the climatically suitable habitat of Juglans regia under different climate change scenarios around the world. Dots indicate the centroids of the suitable habitats of Juglans regia under current climate and different future climate scenarios.

\section{Discussion}

This study was the first to explore the impacts of global climate change on the geographical range and environmentally suitable habitat of the woody oil plant species J. regia in China using MaxEnt modeling. Evaluating the impacts of global climate change scenarios on the potential 
distributions of economically or ecologically essential species will be helpful to understanding the relationships between species niches and the corresponding environment, identifying priority cultivation areas of target species, and setting up effective strategies for species conservation and resource utilization [45-48]. MaxEnt has been commonly implemented for many species to predict potential distribution [49-53]. The results show that the MaxEnt model for J. regia provided an AUC value of 0.843 , indicating a reliable prediction, which is consistent with previous studies [54-56].

The MaxEnt model showed that the geographical distribution of $J$. regia was mostly explained by bioclimatic variables, while the effects of topographical and soil variables were rather small. Previous studies have also confirmed the dominant role of climate in the natural distribution of plants $[57,58]$. Studies on two other cultivated plant species (Scutellaria baicalensis and Tricholoma matsutake) have also found that topographical and soil variables only had a small effect on their distributions $[46,56]$. MTCM and $\mathrm{AP}$ were the most important bioclimatic variables determining the geographical distribution of J. regia and collectively explained $76.5 \%$ of the distribution. J. regia can tolerate a cold environment, but is better suited to humid and warm environments [59]. The habitat suitability of J. regia showed a hump-shaped pattern along the MTCM gradient because the fruits do not mature properly when the effectively accumulated temperature is excessively low or high [59]. The suitable habitats of J. regia predicted under current climate conditions were dominated by humid regions in China (i.e., central and southwestern China), indicating that $J$. Regia favors humid environments.

The MaxEnt model has predicted that J. regia is potentially distributed from $75^{\circ} \mathrm{E}$ to $124^{\circ} \mathrm{E}, 22^{\circ} \mathrm{N}$ to $44^{\circ} \mathrm{N}$ in China under current conditions, consistent with previous findings [60]. Our predictions showed that the potentially suitable climatic distribution of J. regia will expand under all future climate scenarios, indicating that more suitable habitats will be available for the artificial cultivation of $J$. regia in the future. However, J. regia still faces a threat of reduction without proper protection, because the future abundance of $J$. regia will greatly rely on human use. On one hand, J. regia will face a potentially large harvesting probability at different distribution locations, as the market demand of J. regia is rather great in China due to the rich nutrients and oil provided by J. regia. On the other hand, the area size of the environmentally suitable habitat available for the cultivation of J. regia will gradually decrease because of urban development and other social causes. Therefore, future study should incorporate harvesting, land use change, and biotic interactions in the geographical distribution simulation for J. Regia. Additionally, future study can use an entropy and mutual information index-an important concept developed by Shannon in the context of information theory [61] —as an alternative way to define principal variables assessing $J$. regia distribution.

Our predictions also show that J. regia has a high risk of habitat loss in the low latitudes under future climate change, similar to previous findings on bioenergy crops in Europe [62]. More attention and additional protective measures should be placed on the low latitudes. For example, the Chinese government should set nature conservation areas covering the suitable habitats, and reduce human interference in these areas. Our projection reveals that future climate change will cause shifts in the potentially suitable climatic distribution of J. Regia. However, relatively stable distribution sites of woody oil plants are essential for the sustainable supply of feedstocks for oil production $[63,64]$. Therefore, this distribution shift should attract special interest from ecologists.

\section{Conclusions}

J. regia is an important woody oil plant species, and there is urgent demand for its appropriate protection and management. In this study, we developed a habitat suitability model based on the maximum entropy (MaxEnt) theory to evaluate the environmental variables determining the geographical distribution of J. regia and to predict potentially suitable climatic distributions given current and future climate conditions. Our results have shown that J. regia will expand its suitable habitat area size but will face a high risk of habitat loss in the low latitudes in response to global climate change. These results will be valuable to identifying environmentally suitable sites for the reintroduction, cultivation, and management of J. regia. 
Acknowledgments: We acknowledge with great appreciation the support provided by the National Special Water Programs (grant Nos. 2017ZX07101-002, 2015ZX07203-011, 2015ZX07204-007, and 2009ZX07210-009), the Department of Environmental Protection of Shandong Province (SDHBPJ-ZB-08), the Chinese Natural Science Foundation (grant No. 39560023), and the Fundamental Research Funds for the Central Universities (grant No. 2017MS065).

Author Contributions: H.Z. designed the outline of this paper. T.X. collected the data. X.X. completed the calculation using the MaxEnt model. X.X. and J.Y. wrote the paper. Y.X. and Y.T. analyzed data and gaveadvice in the discussion.

Conflicts of Interest: The authors declare no conflict of interest.

\section{Appendix A}

Table A1. Loading factors of 16 bioclimatic variables used in the principal component analysis.

\begin{tabular}{cccc}
\hline Variable & PC1 & PC2 & PC3 \\
\hline Bio1 & 0.282 & -0.234 & -0.214 \\
Bio2 & -0.199 & $\approx 0$ & -0.276 \\
Bio4 & -0.196 & -0.374 & 0.246 \\
Bio5 & 0.102 & -0.491 & $\approx 0$ \\
Bio6 & 0.316 & $\approx 0$ & -0.171 \\
Bio7 & -0.239 & -0.325 & 0.137 \\
Bio8 & 0.149 & -0.444 & -0.153 \\
Bio9 & 0.302 & $\approx 0$ & -0.248 \\
Bio10 & 0.152 & -0.460 & $\approx 0$ \\
Bio11 & 0.308 & $\approx 0$ & -0.272 \\
Bio12 & 0.307 & $\approx 0$ & 0.206 \\
Bio13 & 0.274 & $\approx 0$ & $\approx 0$ \\
Bio16 & 0.293 & 0.114 & $\approx 0$ \\
Bio17 & 0.239 & $\approx 0$ & 0.526 \\
Bio18 & 0.279 & 0.134 & \\
Bio19 & 0.232 & $\approx 0$ & 0.530 \\
\hline
\end{tabular}

PC: principal component calculated from principal component analysis on 16 bioclimatic variables of 543 Juglans regia occurrence points. Descriptions of these variables are given in Table 1.

Table A2. Loading factors of 14 soil variables used in the principal component analysis.

\begin{tabular}{cccc}
\hline Variable & PC1 & PC2 & PC3 \\
\hline t_bulk_den & -0.389 & -0.11 & $\approx 0$ \\
s_bulk_den & -0.422 & $\approx 0$ & -0.185 \\
t_clay & -0.21 & 0.341 & -0.444 \\
s_clay & -0.21 & 0.341 & -0.444 \\
t_gravel & $\approx 0$ & -0.112 & 0.137 \\
s_gravel & -0.177 & $\approx 0$ & $\approx 0$ \\
t_ph_h20 & -0.343 & $\approx 0$ & 0.301 \\
s_ph_h20 & -0.419 & $\approx 0$ & $\approx 0$ \\
t_esp & -0.106 & -0.151 & 0.243 \\
s_esp & $\approx 0$ & $\approx 0$ & 0.242 \\
t_sand & -0.15 & -0.557 & -0.142 \\
s_sand & -0.263 & -0.447 & -0.197 \\
t_silt & -0.202 & 0.318 & 0.468 \\
s_silt & -0.321 & 0.311 & 0.239
\end{tabular}

PC: principal component calculated from principal component analysis on 14 soil variables of 543 Juglans regia occurrence points. Descriptions of these variables are given in Table 1. 
Table A3. Pearson correlation coefficients $(r)$ among four bioclimatic variables calculated using the Band Collection Statistics tool in ArcGIS 10.3.

\begin{tabular}{cccc}
\hline Variable & Bio5 & Bio6 & Bio7 \\
\hline Bio6 & 0.530 & & \\
Bio7 & 0.128 & -0.773 & \\
Bio12 & 0.286 & 0.758 & -0.673 \\
\hline
\end{tabular}

Table A4. Pearson correlation coefficients $(r)$ among 12 soil variables calculated using the Band Collection Statistics tool in ArcGIS 10.3.

\begin{tabular}{|c|c|c|c|c|c|c|c|c|c|c|c|}
\hline Variable & t_bulk_den & s_bulk_den & t_clay & t_gravel & s_gravel & t_ph_h20 & t_esp & s_esp & t_sand & s_sand & t_silt \\
\hline s_bulk_den & 0.415 & & & & & & & & & & \\
\hline t_clay & 0.181 & 0.648 & & & & & & & & & \\
\hline t_gravel & 0.177 & -0.320 & -0.277 & & & & & & & & \\
\hline S_gravel & 0.175 & 0.550 & 0.341 & 0.364 & & & & & & & \\
\hline t_ph_h20 & 0.707 & 0.345 & 0.108 & -0.033 & 0.023 & & & & & & \\
\hline t_esp & 0.083 & 0.189 & 0.141 & -0.084 & 0.064 & 0.305 & & & & & \\
\hline s_esp & 0.058 & 0.192 & 0.176 & -0.220 & -0.020 & 0.295 & 0.772 & & & & \\
\hline t_sand & 0.460 & -0.021 & -0.451 & 0.273 & -0.027 & 0.132 & -0.051 & -0.109 & & & \\
\hline s_sand & 0.363 & 0.748 & 0.133 & -0.175 & 0.399 & 0.219 & 0.127 & 0.098 & 0.535 & & \\
\hline t_silt & 0.251 & -0.016 & 0.121 & 0.017 & 0.003 & 0.440 & 0.057 & 0.145 & -0.534 & -0.479 & \\
\hline s_silt & 0.241 & 0.732 & 0.603 & -0.311 & 0.399 & 0.429 & 0.197 & 0.232 & -0.522 & 0.190 & 0.569 \\
\hline
\end{tabular}

\section{References}

1. IPCC. IPCC Climate Change 2013: The Physical Science Basis. Working Group I Contribution to the Fifth Assessment Report of the Intergovernmental Panel on Climate Change-Summary for Policymakers; IPCC: Geneva, Switzerland, 2013.

2. Despland, E.; Houle, G. Climate influences on growth and reproduction of Pinus banksiana (Pinaceae) at the limit of the species distribution in eastern North America. Am. J. Bot. 1997, 84, 928-937. [CrossRef] [PubMed]

3. Lenoir, J.; Gégout, J.C.; Marquet, P.A.; De, R.P.; Brisse, H. A significant upward shift in plant species optimum elevation during the 20th century. Science 2008, 320, 1768-1771. [CrossRef] [PubMed]

4. $\quad$ Bertrand, R.; Lenoir, J.; Piedallu, C.; Riofríodillon, G.; De, R.P.; Vidal, C.; Pierrat, J.C.; Gégout, J.C. Changes in plant community composition lag behind climate warming in lowland forests. Nature 2011, 479, 517. [CrossRef] [PubMed]

5. Dion, P.-P.; Bussières, J.; Lapointe, L. Sustainable leaf harvesting and effects of plant density on wild leek cultivation plots and natural stands in Southern Quebec, Canada. Agrofor. Syst. 2016, 90, 979-995. [CrossRef]

6. Lu, C.Y.; Gu, W.; Dai, A.H.; Wei, H.Y. Assessing habitat suitability based on geographic information system (GIS) and fuzzy: A case study of Schisandra sphenanthera Rehd. et Wils. in Qinling Mountains, China. Ecol. Model. 2012, 242, 105-115. [CrossRef]

7. Guo, Y.; Wei, H.; Lu, C.; Gao, B.; Gu, W. Predictions of potential geographical distribution and quality of Schisandra sphenanthera under climate change. PeerJ 2016, 4, e2554. [CrossRef] [PubMed]

8. Hakl, J.; Fuksa, P.; Konečná, J.; Pacek, L.; Tlustoš, P. Effect of applied cultivation technology and environmental conditions on lucerne farm yield in the Central Europe. Plant Soil Environ. 2014, 60, 475-480. [CrossRef]

9. Lamb, J.F.S.; Jung, H.-J.G.; Riday, H. Growth environment, harvest management and germplasm impacts on potential ethanol and crude protein yield in alfalfa. Biomass Bioenergy 2014, 63, 114-125. [CrossRef]

10. Anderson, R.P. A framework for using niche models to estimate impacts of climate change on species distributions. Ann. N. Y. Acad. Sci. 2013, 8-28. [CrossRef] [PubMed]

11. Martin, Y.; Titeux, N. Testing instead of assuming the importance of land use change scenarios to model species distributions under climate change. Glob. Ecol. Biogeogr. 2013, 22, 1204-1216. [CrossRef]

12. Qin, Z.; Zhang, J.E.; Ditommaso, A.; Wang, R.L.; Liang, K.M. Predicting the potential distribution of Lantana camara L. under RCP scenarios using ISI-MIP models. Clim. Chang. 2016, 134, 193-208. [CrossRef]

13. Wang, H.H.; Wonkka, C.L.; Grant, W.E.; Rogers, W.E. Potential range expansion of Japanese honeysuckle (Lonicera japonica thunb.) in southern U.S. forestlands. Forests 2012, 3, 573-590. [CrossRef] 
14. Wang, W.; Tang, X.; Zhu, Q.; Pan, K.; Hu, Q.; He, M.; Li, J. Predicting the impacts of climate change on the potential distribution of major native non-food bioenergy plants in China. PLoS ONE 2014, 9, 1-11. [CrossRef] [PubMed]

15. Yuan, H.-S.; Wei, Y.-L.; Wang, X.-G. Maxent modeling for predicting the potential distribution of Sanghuang, an important group of medicinal fungi in China. Fungal Ecol. 2015, 17, 140-145. [CrossRef]

16. Li, G.; Xu, G.; Guo, K.; Du, S. Mapping the global potential geographical distribution of black locust (Robinia Pseudoacacia L.) using herbarium data and a maximum entropy model. Forests 2014, 5, 2773-2792. [CrossRef]

17. Xu, X.; Zhang, H.; Xie, T.; Xu, Y.; Zhao, L.; Tian, W. Effects of climate change on the potentially suitable climatic geographical range of Liriodendron chinense. Forests 2017, 8, 399. [CrossRef]

18. Rundel, P.W. Modeled shifts in Polylepis species ranges in the Andes from the Last Glacial Maximum to the present. Forests 2017, 8, 232.

19. Deb, J.C.; Phinn, S.; Butt, N.; Mcalpine, C.A. Climatic-induced shifts in the distribution of Teak (Tectona grandis) in tropical Asia: Implications for forest management and planning. Environ. Manag. 2017, 60, 422-435. [CrossRef] [PubMed]

20. Dai, G.; Yang, J.; Huang, C.; Sun, C.; Jia, L.; Ma, L. The effects of climate change on the development of tree plantations for biodiesel production in China. Forests 2017, 8, 207. [CrossRef]

21. Hernandez, P.A.; Graham, C.H.; Master, L.L.; Albert, D.L. The effect of sample size and species characteristics on performance of different species distribution modeling methods. Ecography 2006, 29, 773-785. [CrossRef]

22. Pearson, R.G.; Raxworthy, C.J.; Nakamura, M.; Peterson, A.T. Predicting species distributions from small numbers of occurrence records: A test case using cryptic geckos in Madagascar. J. Biogeogr. 2007, 34, 102-117. [CrossRef]

23. Merow, C.; Smith, M.J.; Silander, J.A. A practical guide to MaxEnt for modeling species' distributions: What it does, and why inputs and settings matter. Ecography 2013, 36, 1058-1069. [CrossRef]

24. Zhang, Y.; Yuan, S.; Wang, X.; Feng, B.; Zhang, R.; Han, J. Analysis and reflection on development strategy of walnut processing industry in China. Trans. Chin. Soc. Agric. Eng. 2015, 31, 1-8, (in Chinese with English abstract).

25. Crews, C.; Hough, P.; Godward, J.; Brereton, P.; Lees, M.; Guiet, S.; Winkelmann, W. Study of the main constituents of some authentic walnut oils. J. Agric. Food Chem. 2005, 53, 4853-4860. [CrossRef] [PubMed]

26. Xi, R.T. The textual research on the origin of Chinese walnut (Juglans regia L.). J. Hebei Univ. Agric. 1990, 13, 89-94, (in Chinese with English abstract).

27. USDA-FAS. Oilseeds: World Markets and Trade, 07-10-2015. 2015. Available online: http://usda.mannlib. cornell.edu/usda/fas/oilseed-trade/ /2010s / 2015/oilseed-trade-07-10-2015.pdf..

28. Yuan, S.J. Developing situation and countermeasures of Shaanxi walnut industry. Shaanxi For. 2009, 6, 10, (In Chinese with English abstract).

29. Chinese Virtual Herbarium. Available online: http:/ / www.cvh.ac.cn/ (accessed on 24 July 2017).

30. Global Biodiversity Information Facility. Available online: http:/ /www.gbif.org/ (accessed on 24 July 2017).

31. Hijmans, R.J.; Cameron, S.E.; Parra, J.L.; Jones, P.G.; Jarvis, A. Very high resolution interpolated climate surfaces for global land areas. Int. J. Climatol. 2005, 25, 1965-1978. [CrossRef]

32. Varela, S.; Lima-Ribeiro, M.S.; Terribile, L.C. A short guide to the climatic variables of the last glacial maximum for biogeographers. PLoS ONE 2015, 10, e0129037. [CrossRef] [PubMed]

33. Bedia, J.; Herrera, S.; Gutiérrez, J.M. Dangers of using global bioclimatic datasets for ecological niche modeling. Limitations for future climate projections. Glob. Planet. Chang. 2013, 107, 1-12. [CrossRef]

34. Fischer, G.; Nachtergaele, F.; Prieler, S.; Van Velthuizen, H.T.; Verelst, L.; Wiberg, D. Global Agro-Ecological Zones Assessment for Agriculture (GAEZ 2008); IIASA: Laxenburg, Austria; FAO: Rome, Italy, 2008.

35. Xin, X.; Zhang, L.; Zhang, J.; Wu, T.; Fang, Y. Climate change projections over East Asia with BCC_CSM1.1, climate model under RCP scenarios. J. Meteorol. Soc. Japan 2013, 91, 413-429. [CrossRef]

36. Rana, S.K.; Rana, H.K.; Ghimire, S.K.; Shrestha, K.K.; Ranjitkar, S. Predicting the impact of climate change on the distribution of two threatened Himalayan medicinal plants of Liliaceae in Nepal. J. Mt. Sci. 2017, 14, 558-570. [CrossRef]

37. Heikkinen, R.K.; Luoto, M.; Araújo, M.B.; Virkkala, R.; Thuiller, W.; Sykes, M.T. Methods and uncertainties in bioclimatic envelope modelling under climate change. Prog. Phys. Geogr. 2006, 30, 751-777. [CrossRef]

38. Yang, X.Q.; Kushwaha, S.P.S.; Saran, S.; Xu, J.; Roy, P.S. Maxent modeling for predicting the potential distribution of medicinal plant, Justicia adhatoda L. in Lesser Himalayan foothills. Ecol. Eng. 2013, 51, 83-87. 
39. Phillips, S.J.; Anderson, R.P.; Schapire, R.E. Maximum entropy modeling of species geographic distributions. Ecol. Model. 2006, 190, 231-259. [CrossRef]

40. Elith, J.; Graham, C.H.; Anderson, R.P.; Dudík, M.; Ferrier, S.; Guisan, A.; Hijmans, R.J.; Huettmann, F.; Leathwick, J.R.; Lehmann, A.; et al. Novel methods improve prediction of species' distributions from occurrence data. Ecography 2006, 29, 129-151. [CrossRef]

41. Phillips, S.J.; Dudík, M. Modeling of species distributions with Maxent: New extensions and a comprehensive evaluation. Ecography 2008, 31, 161-175. [CrossRef]

42. Manel, S.; Williams, H.C.; Ormerod, S.J. Evaluating presence-absence models in ecology: The need to account for prevalence. J. Appl. Ecol. 2001, 38, 921-931. [CrossRef]

43. Jiménez-Valverde, A.; Lobo, J.M. Threshold criteria for conversion of probability of species presence to either-or Presence-Absence. Acta Oecol. 2007, 31, 361-369. [CrossRef]

44. Aguirre-Gutiérrez, J.; Kissling, W.D.; Carvalheiro, L.G.; WallisDeVries, M.F.; Franzén, M.; Biesmeijer, J.C. Functional traits help to explain half-century long shifts in pollinator distributions. Sci. Rep. 2016, 6. [CrossRef] [PubMed]

45. Davies, T.J.; Purvis, A.; Gittleman, J.L. Quaternary climate change and the geographic ranges of mammals. Am. Nat. 2009, 174, 297-307. [CrossRef] [PubMed]

46. Zhang, L.; Cao, B.; Bai, C.; Li, G.; Mao, M. Predicting suitable cultivation regions of medicinal plants with Maxent modeling and fuzzy logics: A case study of Scutellaria baicalensis in China. Environ. Earth Sci. 2016, 75, 1-12. [CrossRef]

47. Pearce, J.; Lindenmayer, D. Bioclimatic analysis to enhance reintroduction biology of the endangered Helmeted Honeyeater (Lichenostomus melanops cassidix) in Southeastern Australia. Restor. Ecol. 1998, 6, 238-243. [CrossRef]

48. Aguilar-Soto, V.; Melgoza-Castillo, A.; Villarreal-Guerrero, F.; Wehenkel, C.; Pinedo-Alvares, C. Modeling the potential distribution of Picea chihuahuana Martínez, an endangered species at the Sierra Madre Occidental, Mexico. Forests 2015, 6, 692-707. [CrossRef]

49. Nabout, J.C.; Magalhães, M.R.; Ma, D.A.G.; Da, C.H. The impact of global climate change on the geographic distribution and sustainable harvest of Hancornia speciosa Gomes (Apocynaceae) in Brazil. Environ. Manag. 2016, 57, 1-8. [CrossRef] [PubMed]

50. Elith, J.; Phillips, S.J.; Hastie, T.; Dudík, M.; Chee, Y.E.; Yates, C.J. A statistical explanation of MaxEnt for ecologists. Divers. Distrib. 2011, 17, 43-57. [CrossRef]

51. Noulèkoun, F.; Chude, S.; Zenebe, A.; Birhane, E. Climate change impacts on Faidherbia albida (Delile) A. Chev. distribution in dry lands of Ethiopia. Afr. J. Ecol. 2017, 55, 233-243.

52. Narouei-Khandan, H.A. Ensemble Models to Assess the Risk of Exotic Plant Pathogens in a Changing Climate. Ph.D. Thesis, Lincoln University: Lincoln, New Zealand, 2014.

53. Huang, J.; Li, G.; Li, J.; Zhang, X.; Yan, M.; Du, S. Projecting the Range Shifts in Climatically Suitable Habitat for Chinese Sea Buckthorn under Climate Change Scenarios. Forests 2017, 9, 9. [CrossRef]

54. Ray, D.; Behera, M.D.; Jacob, J. Indian Brahmaputra valley offers significant potential for cultivation of rubber trees under changed climate. Curr. Sci. 2014, 107, 461-469.

55. Yi, Y.J.; Cheng, X.; Yang, Z.F.; Zhang, S.H. Maxent modeling for predicting the potential distribution of endangered medicinal plant (H. riparia Lour) in Yunnan, China. Ecol. Eng. 2016, 92, 260-269. [CrossRef]

56. Guo, Y.; Li, X.; Zhao, Z.; Wei, H.; Gao, B.; Wei, G. Prediction of the potential geographic distribution of the ectomycorrhizal mushroom Tricholoma matsutake under multiple climate change scenarios. Sci. Rep. 2017, 7, 46221. [CrossRef] [PubMed]

57. Pearson, R.G.; Dawson, T.P. Predicting the impacts of climate change on the distribution of species: Are bioclimate envelope models useful? Glob. Ecol. Biogeogr. 2003, 12, 361-371. [CrossRef]

58. Kelly, A.E.; Goulden, M.L. Rapid shifts in plant distribution with recent climate change. Proc. Natl. Acad. Sci. USA 2008, 105, 11823-11826. [CrossRef] [PubMed]

59. Han, H.; Luo, C.; Zhu, Y.; Wu, W.; Zhang, Q.; Du, G. Planting regionalization and ecological adaptability of walnut in Sichuan province. J. West China For. Sci. 2012, 3, 2, (in Chinese with English abstract).

60. Xi, S. Gene resources of Juglans and genetic improvement of Juglans regia in China. Sci. Silvae Sin. 1987, 23, 342-350, (in Chinese with English abstract).

61. Arellano-Valle, R.B.; Contreras-Reyes, J.E.; Genton, M.G. Shannon entropy and mutual information for multivariate skew-elliptical distributions. Scand. J. Stat. 2013, 40, 42-62. [CrossRef] 
62. Tuck, G.; Glendining, M.J.; Smith, P.; House, J.I.; Wattenbach, M. The potential distribution of bioenergy crops in Europe under present and future climate. Biomass Bioenergy 2006, 30, 183-197. [CrossRef]

63. Evans, J.M.; Fletcher, R.J.; Alavalapati, J. Using species distribution models to identify suitable areas for biofuel feedstock production. GCB Bioenergy 2010, 2, 63-78. [CrossRef]

64. Trabucco, A.; Achten, W.M.J.; Bowe, C.; Aerts, R.; Orshoven, J.; Van Norgrove, L.; Muys, B. Global mapping of Jatropha curcas yield based on response of fitness to present and future climate. GCB Bioenergy 2010, 2 , 139-151. [CrossRef]

(C) 2018 by the authors. Licensee MDPI, Basel, Switzerland. This article is an open access article distributed under the terms and conditions of the Creative Commons Attribution (CC BY) license (http://creativecommons.org/licenses/by/4.0/). 